\title{
Cementless modular total hip arthroplasty with subtrochanteric transverse shortening osteotomy for high hip dislocations
}

\author{
Erhan Sukur ${ }^{1 *}$, Ahmet Senel ${ }^{2}$, Ugur Ozdemir ${ }^{1}$, Yunus Emre Akman³ ${ }^{3}$ Ibrahim Azboy ${ }^{4}$ and Yusuf Ozturkmen ${ }^{2}$
}

\begin{abstract}
Background: Performing a total hip arthroplasty for a high hip dislocation is technically demanding and presents several challenges, with appropriate evaluation of the bone morphology of the hip and proper implant selection being critical for successful outcomes.

Objective: The purpose of our study was to evaluate the clinical and radiographic outcomes of cementless modular total hip arthroplasty for the treatment of high hip dislocations with sub-trochanteric transverse shortening osteotomy.

Methods: Sixty-eight hips with a high hip dislocation, were treated using a sub-trochanteric transverse shortening osteotomy and cementless modular total hip arthroplasty, retrospectively reviewed. Hip function was assessed using the Harris hip score, with hip abduction strength evaluated using the Trendelenburg test. Radiographic assessment included the measurement of leg length discrepancy, identification of implant loosening, localization of the hip center, and union at the osteotomy site.
\end{abstract}

Results: The mean follow-up period was 12.9 (range 5.2-16.8) years. The mean Harris hip score improved from a preoperative score of $48.6 \pm 3.6$ to $82.4 \pm 4.2(p<0.05)$. The hip was within the true acetabulum in all patients, postoperatively. Osteotomy union was achieved in 67 of the 68 hips (98.5\%) in a mean latency of $12.5 \pm 0.6$ weeks. The mean length of femoral shortening was $66.5 \pm 4.5 \mathrm{~mm}$, with a mean pull-down length of the proximal part of $35.5 \pm 3.5 \mathrm{~mm}$.

Conclusion: For the treatment of high hip dislocations with satisfactory clinical outcomes, the modular stem offers an adjustable anteversion angle to restore sufficient rotational stability and the transverse osteotomy provides sufficient compression pressure across the osteotomy site to facilitate union.

Trial registration It was a retrospective study and approved by Istanbul Research and Training Hospital institutional Ethics Review Board (772-05/02/2016).

Keywords: High hip dislocation, Modular, Transverse osteotomy

*Correspondence: erhan_sukur@hotmail.com

${ }^{1}$ Departments of Orthopaedics and Traumotology, Sakarya University Training and Research Hospital, 54050 Sakarya, Turkey

Full list of author information is available at the end of the article

\begin{abstract}
Background
Performing total hip arthroplasty (THA) for high hip dislocation is technically demanding and presents several challenges to surgeons. Indeed, appropriate evaluation of the hip bone structure and proper implant selection are critical to successful outcomes [1-3]. The difficulties in identifying and preparing the acetabulum and achieving stable fixation of the acetabular component are well
\end{abstract} original author(s) and the source, provide a link to the Creative Commons licence, and indicate if changes were made. The images or other third party material in this article are included in the article's Creative Commons licence, unless indicated otherwise in a credit line to the material. If material is not included in the article's Creative Commons licence and your intended use is not permitted by statutory regulation or exceeds the permitted use, you will need to obtain permission directly from the copyright holder. To view a copy of this licence, visit http://creativecommons.org/licenses/by/4.0/. The Creative Commons Public Domain Dedication waiver (http://creativeco mmons.org/publicdomain/zero/1.0/) applies to the data made available in this article, unless otherwise stated in a credit line to the data. 
described in the literature [1,4-8]. When considering the femur, the most notable morphological variations are excessive femoral anteversion and a high valgus neckshaft angle that reduces acetabular coverage of the femoral head [1]. Moreover, dysplastic femurs have a small diaphyseal diameter that requires careful stem selection [9].

A key component of acetabular reconstruction is the restoration of the anatomical hip center, with reduction of the femoral head into the true acetabulum being important in achieving better hip biomechanics and bone support for implantation, as well as longer THA survival $[3,4,10]$. However, achieving and maintaining reduction of the femoral head into the true acetabulum is difficult in patients with high hip dislocations due to severe soft tissue contracture, leg length discrepancy, impairment in abductor muscle function, and abnormal bone morphology [10]. Sub-trochanteric osteotomy and femoral shortening have been performed using a pull-down technique to address these complications [3,11-13]. In these cases, achieving rotational stability and compression at the osteotomy site is essential in preventing non-union [14]. However, obtaining a straight femoral canal and selecting the appropriate fit and fill implant is difficult using mono-block femoral implants [4]. Fitting of the femoral implant is further complicated by the sub-trochanteric osteotomy itself, which produces incongruence between the diameters of the metaphyseal and diaphyseal canals, increasing the risk for non-union [4, 15-18].

A modular femoral stem can improve fitting in a straight and narrow femoral canal, stabilizing both the metaphyseal and diaphyseal components to provide sufficient torsional stability across the osteotomy site [11]. Additionally, the different pairing of sleeve and handle of the femoral components with a modular stem is beneficial to correct excessive anteversion [11]. Therefore, we aimed to evaluate the clinical and radiographic outcomes of cementless modular THAs to treat high hip dislocations with sub-trochanteric transverse shortening osteotomy.

\section{Materials and Methods}

This retrospective study was approved by Istanbul Research and Training Hospital institutional Ethics Review Board (2016-772). Between October 2001 and February 2012, 56 patients (68 hips) with Crowe type IV-Hartofilakidis type III high hip dislocations were treated using a sub-trochanteric, transverse shortening osteotomy, and cementless modular THA $[19,20]$. All patients were female, with a mean age of 48.2 (range 36-64) years. Forty-four patients (78.6\%) presented with unilateral hip dysplasia, with the remaining 12 (21.4\%) presenting with bilateral hip dysplasia. There was a 3-month interval between the two surgeries. Relevant demographic and pre-operative clinical features of the study group are summarized in Table 1 . The indications for THA included severe hip pain and functional impairment in daily activities, as well as abnormal gait due to leg length discrepancy and abductor weakness.

Routine follow-up examinations were performed in the first, fourth, and twelfth months postoperatively. The final status of the patients was obtained from the latest available outpatient records. Pre-operative clinical and radiographic assessments were performed during the latest follow-up examinations. Hip function and hip abductor strength were assessed using the Harris hip score (HHS) and the Trendelenburg test, respectively [21]. Leg length was measured as the distance between the anterior superior iliac spine and the medial malleolus. Complications were noted at each follow-up visit.

The radiographic assessment included anteroposterior and lateral hip views to measure leg length discrepancy after surgery, identification of implant loosening and migration, localization of the anatomical hip center, and determination of bony union at the osteotomy site. The change in leg length from pre- to post-operation was calculated using the pulled down distance (vertical distance from the tip of the greater trochanter to the teardrop line) and the length of femoral shortening [10]. The location of the anatomical hip center was defined as the vertical distance between the ischial tuberosity and the center of the femoral head. Femoral component stability was classified according to the criteria of Engh et al. [22] as follows: fixation by bony ingrowth, stable fibrous ingrowth and unstable fibrous ingrowth. Serial radiographs were assessed by a single surgeon to evaluate union (bridging of the bone trabeculae) at the osteotomy site.

Two femoral components were used in this study: the straight cylindrical cementless component with a proximal porous coating (Helios, Valencia, Biomet, Spain) (Fig. 1) was used in 39 patients (47 hips) between 2001 and 2011, and the modular femoral revision stem (Arcos, Zimmer, Biomet) (Fig. 2) in 17 patients (21 hips) between 2011 and 2012. A porous-coated acetabular component with a dome screw (Exceed AB Acetabular Cup, Zimmer, Biomet) was used in all patients with metal-on-polyethylene bearing surfaces.

Table 1 Demographic data of patients

\begin{tabular}{ll}
\hline Number of patients/hips & $56 / 68$ \\
Bilateral/unilateral hip & $12(21.4 \%) / 44(78.6 \%)$ \\
Age (years) & 48.2 (range 36-64) \\
Gender; female/male & $56 / 0$ \\
Mean follow up (years) & 12.9 (range 5.2-16.8) \\
\hline
\end{tabular}



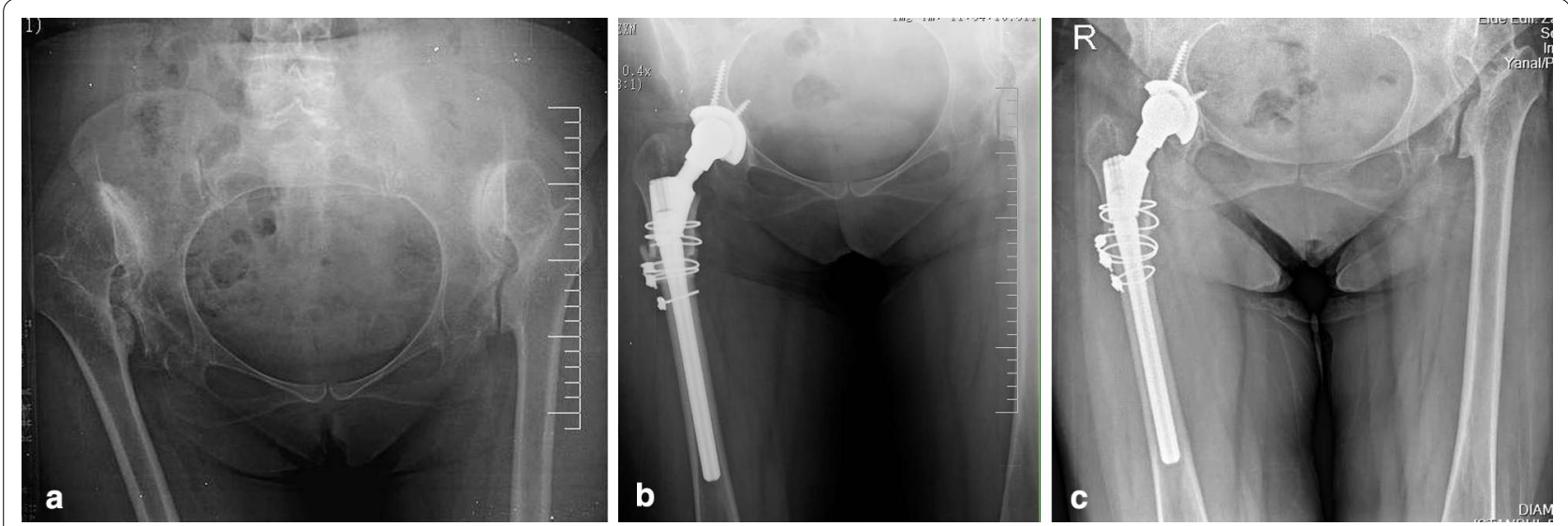

Fig. 1 Radiographs of a 54 years old female with high hip dislocation. a Preoperative anteroposterior view. b Early postoperative radiographic image. Hip was reconstructed at the level of the anatomic hip center by cementless modular (Helios, Valencia, Biomet, Spain) total hip arthroplasty combined with transverse osteotomy and the osteotomy site was wrapped with the osteotomy fragments, stabilized using cerclage wires. Reconstruction of the acetabulum with screws was performed. c Postoperative radiographic image at 16-month follow-up, bone union was detected at the osteotomy site and no radiolucent lines around the femoral stem were found
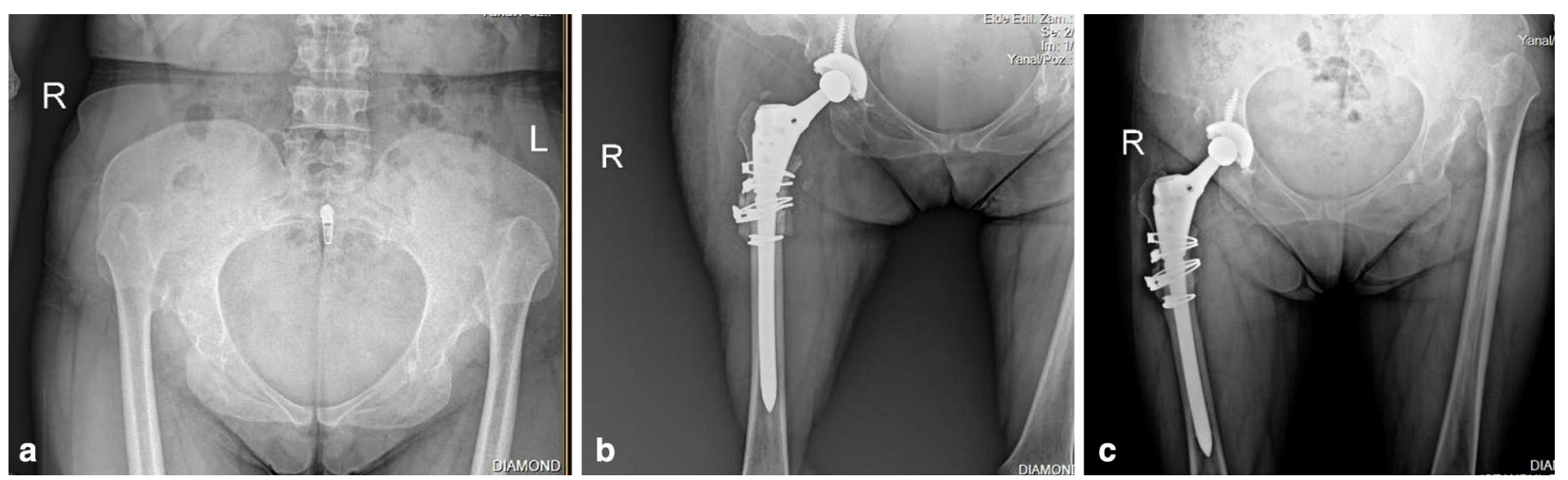

Fig. 2 Radiographs of a 48 years old female with high hip dislocation. a Preoperative anteroposterior view. $\mathbf{b}$ Early postoperative radiographic image. Hip was reconstructed at the level of the anatomic hip center by cementless modular (Arcos, Zimmer, Biomet) total hip arthroplasty combined with transverse osteotomy and the osteotomy site was wrapped with the osteotomy fragments, stabilized using cerclage wires. $\mathbf{c}$ Postoperative radiographic image at 3 years follow-up, bone union was detected at the osteotomy site and no radiolucent lines around the femoral stem were found

\section{Surgical technique}

A posterolateral approach was used with distal extension to access the proximal femoral shaft. The sciatic nerve was identified and protected. Following total capsulectomy, reaming and rasping of the femoral canal was performed before femoral osteotomy and acetabular preparation. The surface of the femoral shaft was marked with a bone chisel, from proximal to distal, to guide rotation of the femoral shaft during implantation. A transverse osteotomy was performed using a motor saw, approximately $1 \mathrm{~cm}$ below the inferior surface of the lesser trochanter and perpendicular to the femoral shaft as previously described by Masonis et al. [17]. The proximal fragment of the femur was retracted in a cephalo-lateral direction to facilitate soft tissue dissection and provide adequate exposure of the acetabulum. The acetabular component was positioned in the true acetabular region, as described by Sener et al. [16], with the true acetabulum identified by dissecting the joint capsule to the inferior of the acetabulum to locate the transverse acetabular ligament. The acetabular component was then implanted in the true acetabulum and fixed with a dome screw. The proximal part of the femoral component having the largest offset and best fit in the proximal fragment was selected. Once implanted, a trial hip reduction was performed to determine where to cut the distal part of the femur overlapping with the proximal part. The overlap length of bone was removed by osteotomy. 
The amount of femoral shortening was planned so that the lower limb would be lengthened by no more than $3 \mathrm{~cm}$. The resected bone fragment was divided in the midline and opened like a book for wrapping around the osteotomy site. The canal of the distal femoral fragment was prepared using rasping until a secure fixation was obtained. After reduction with the actual stem, the rigid rotational stability of the stem was checked at both

Table 2 Clinical results

\begin{tabular}{|c|c|c|c|}
\hline & Pre-operative & Postoperative & ${ }^{*} p$-value \\
\hline \multicolumn{4}{|l|}{ Harris Hip score } \\
\hline Mean score (range) & $\begin{array}{l}48.6 \pm 3.6 \\
(34-66)\end{array}$ & $\begin{array}{l}82.4 \pm 4.2 \\
(72-92)\end{array}$ & $<0.05$ \\
\hline \multicolumn{4}{|l|}{ Rating $(n)$} \\
\hline Excellent & 0 & 22 & \\
\hline Good & 5 & 23 & \\
\hline Fair & 15 & 5 & \\
\hline Poor & 34 & 4 & \\
\hline \multicolumn{4}{|l|}{$\operatorname{Limp}(n)$} \\
\hline Severe & 36 & 4 & \\
\hline Moderate & 10 & 6 & \\
\hline Slight & 8 & 25 & \\
\hline None & 0 & 19 & \\
\hline \multicolumn{4}{|l|}{ Limb length discrepancy } \\
\hline Mean (range) (mm) & $43(35-60)$ & $5(1-15)$ & $<0.005$ \\
\hline \multicolumn{4}{|l|}{$* *(n)$} \\
\hline$<1 \mathrm{~cm}$ & 0 & 37 & \\
\hline $1-2 \mathrm{~cm}$ & 0 & 7 & \\
\hline$>2 \mathrm{~cm}$ & 44 & 0 & \\
\hline $\begin{array}{l}\text { Positive Trendelenburg } \\
\text { sign }(n)\end{array}$ & 54 & 11 & \\
\hline
\end{tabular}

*Statistical significance was set at $p<0.05,{ }^{* *}$ Recorded only for patients with unilateral high hip dislocations the proximal and distal sites. Efforts were made to ensure maximum bone contact at the osteotomy line. Additionally, the osteotomy site was wrapped with the osteotomy fragments and stabilized using 2 cables in most cases.

\section{Statistical analysis}

Two-sided, paired Student's $t$-test was used to analyze pre- and postoperative HHS and clinical and radiological measurements after confirming the normal distribution and equal variance of the data. Statistical significance was set at $p<0.05$.

\section{Results}

Demographic data of enrolled patients are summarized in Table 1. The mean follow-up period was 12.9 (range 5.2-16.8) years. The mean HHS improved from a preoperative score of $48.6 \pm 3.6$ to $82.4 \pm 4.2$ at the most recent follow-up time point $(p<0.05$; Table 2$)$.

The postoperative anatomical hip center was within the true acetabulum in all patients (Fig. 3a, b, c). Osteotomy union was achieved in 67 of the 68 hips (98.5\%) in a mean latency of $12.5 \pm 0.6$ weeks (Figs. 1, 2, 3). The mean length of femoral shortening was $66.5 \pm 4.5 \mathrm{~mm}$, with a mean pull-down length of the proximal part of $35.5 \pm 3.5 \mathrm{~mm}$. While the pre-operative number of patients with a positive Trendelenburg sign was 54, this number was reduced to 11 after surgery.

Complications were observed in 9 (13.2\%) hips, with revision surgery performed in 8 (11.7\%) of these cases. Posterior hip dislocation was encountered in 1 patient, requiring open reduction and replacement of the femoral stem to adjust the anteversion angle. Femoral revision, using a larger femoral stem, was performed in 2 hips in the early postoperative period due to non-union and rotational instability at the osteotomy site. A two-stage
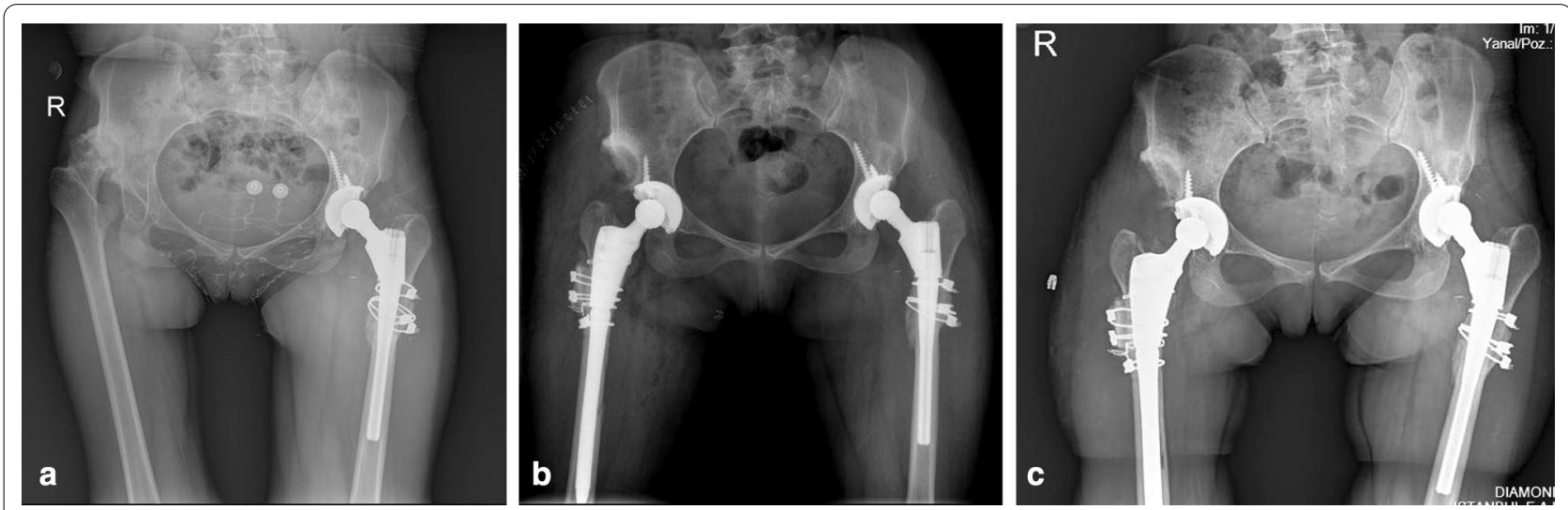

Fig. 3 Radiographs of a 62 years old female with high hip dislocation. a Preoperative anteroposterior view. b Early postoperative radiographic image. Asetabuler componenet was reconstructed in the true acetabulum with transverse osteotomy. c Postoperative radiographic image at 5 years follow-up, bone union was detected at the osteotomy site 
revision was performed in 2 hips due to septic loosening. A revision was performed in 1 patient in the $3^{\text {rd }}$ postoperative year due to aseptic loosening of the femoral stem and in the $5^{\text {th }}$ postoperative year due to acetabular loosening. One case of sciatic nerve dysfunction was observed, although partial recovery was achieved. Fracture of the greater trochanter occurred in 1 hip, which was treated with a trochanteric plate and cable grip at the early postoperative period, with bony union achieved at the $8^{\text {th }}$ postoperative week (Fig. 4).

\section{Discussion}

We provide evidence for the feasibility of using a cementless and modular THA, combined with sub-trochanteric transverse shortening osteotomy, as a treatment option for high hip Crowe type IV-Hartofilakidis type III dislocations. Here we show a low incidence of complications and good clinical outcomes. The strengths of our study include a mean follow-up of 12.9 years; analysis based on consecutive hips classified solely using Crowe type IVHartofilakidis type III; use of the same acetabular cup, modular and cementless femoral stem designs, and a uniform type of transverse osteotomy performed in all cases. Previous studies evaluating cementless THA with subtrochanteric femoral osteotomy for high hip dislocations have included different types of osteotomy and implants. Only two, however, have exclusively evaluated outcomes for Crowe type IV-Hartofilakidis type III dislocations using a modular femoral stem $[10,23]$.

Placement of the acetabular component in the true acetabulum improves the lever arm of the hip abductor muscles and lowers the risk of loosening of the acetabular component, which is increased by a vertical displacement of the hip center [23-25]. We achieved implantation of the acetabular component in the true acetabulum in all cases, with only 1 case of acetabular loosening identified 5 years postoperatively. Reduction of the femoral head to the anatomical hip center performed without femoral shortening increases the risk for neural and neurovascular complications due to the magnitude of distraction required $[3,8,12,25,26]$. A leg lengthening of $>3 \mathrm{~cm}$ after implantation has been suggested as an indication for sub-trochanteric shortening osteotomy [10]. In our case series, the mean pull-down length of the proximal part and shortening length of the femur were $66.5 \pm 4.5 \mathrm{~mm}$ and $35.5 \pm 3.5 \mathrm{~mm}$, respectively. Indeed, Kilicoglu et al. [12] and Sofu et al. [27] have reported a pull-down length of $45 \mathrm{~mm}$ and $46 \mathrm{~mm}$, respectively, without incidence of nerve palsy. We had 1 case of sciatic nerve dysfunction, where only partial recovery was achieved.

The non-union of the osteotomy is a common complication after sub-trochanteric shortening osteotomy due to poor resistance against applied rotational and axial bending force. Previously reported rates of non-union for high hip dislocations range between $2.8 \%$ and $7.1 \%$ [ $28-$ $31]$. The risk of a delayed union can be lowered by appropriate selection of the type of osteotomy and femoral stem implant [12]. Yasgur et al. [15] have suggested augmenting the osteotomy site with allograft struts and cable wires, regardless of the osteotomy type, to maintain rotational stability. Akiyama et al. [32] recommended additional plate fixation to maintain torsional stability with cementless conventional stems after transverse shortening osteotomies. In their evaluation of 44 patients with developmental dislocation of the hip treated by THA, using cementless non-modular stems with a transverse
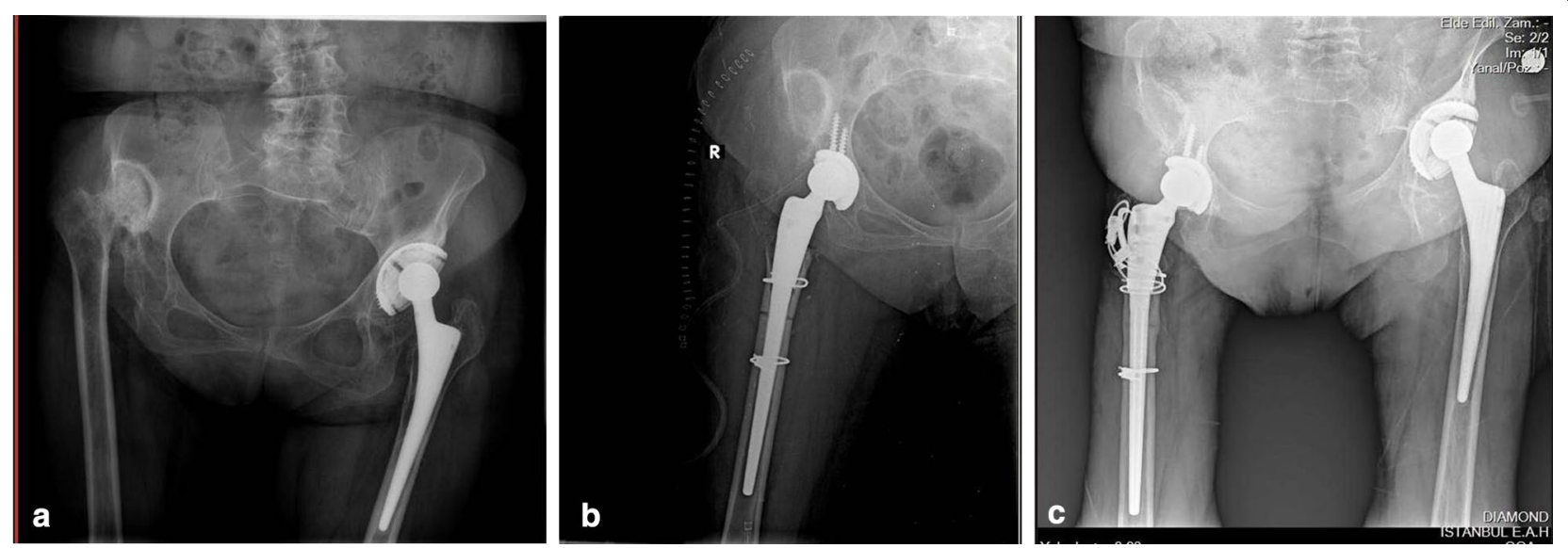

Fig. 4 Radiographs of a 53 years old female with high hip dislocation. a Preoperative anteroposterior view. b Early postoperative radiographic image. Hip was reconstructed at the level of the anatomic hip center by cementless modular total hip arthroplasty combined with transverse osteotomy. Trochanter major fracture was observed and treated with trochanteric plate and cable grip, with bony union achieved at the 8th postoperative week (c) 
femoral shortening osteotomy, Yalçın et al. [33] used a plate and screws for additional stabilization of the osteotomy site in 10 cases. The 5 cases of non-union identified in their series occurred in patients in whom plate and screw stabilization had not been used. Based on their experience, these authors recommended performing internal fixation with plate and screws to provide additional rotational stability and lower the risk of non-union and malalignment at the osteotomy site $[15,17]$. Of further concern is the relatively small contact surface with transverse osteotomies [23], with retraction of the gluteus medius muscle, and thus of the proximal femoral segment, enlarging the gap at the osteotomy site. Therefore, sufficient compression across the osteotomy site is necessary to prevent distraction [14]. In their biomechanical comparison of 4 types of sub-trochanteric osteotomies, Muratli et al. [34] could not identify specific features that could increase stability. Furthermore, in a meta-analysis by $\mathrm{Li}$ et al. [35], no significant differences between transverse and modified osteotomies with regard to the rate of complication and survival were found. The transverse osteotomy, however, provides a technically simpler method to correct the angle of femoral anteversion, with minimal periosteal damage at the osteotomy site [23, 35]. A transverse osteotomy also provides several other advantages, including preservation of the proximal femoral metaphysis and simultaneous shortening and correction of femoral anteversion [11]. In our case series, we exclusively used a transverse osteotomy, with a nonunion rate at the osteotomy site of $2.9 \%$. In our experience, the combination of transverse osteotomy and the use of a modular type of femoral stem provides the best option to lower the risk of non-union. Modular stems provide press-fit fixation for both the proximal and distal femoral components, individually, with the wide range of sizes of the proximal and distal components facilitating sufficient rotational stability and compression at the osteotomy site [36, 37]. By comparison, rigid fixation is not possible with conventional cementless femoral components due to the mismatch between the proximal and the distal cortices [23]. Moreover, the ability to place the proximal segment of the femoral component separately from the diaphyseal segment, including fixation of the proximal segment with a stepped sleeve with modular stem, is beneficial for correction of excessive anteversion [11], which is common even in cases of mild hip dysplasia and is associated with an increased risk for subluxation post-THA [1]. Additionally, in many of these cases, the proximal femur may be too narrow for a fit and fill style implant (broached body). This limitation is overcome with the use of modular femoral stems, which provide
3 different tapered stem sizes with 4 different vertical height options, allowing the proximal femoral canal to be prepared after the distal component is implanted to achieve the desired vertical offset and version correction. In our case series, we corrected femoral anteversion using a modular stem through in situ distraction and rotation of the proximal segment relative to the distal segment. In cases with a $>20^{\circ}$ of anteversion, de-rotation was combined with a modular metaphyseal sleeve at the osteotomy site. With our approach, we encountered only 1 case of dislocation in the early postoperative period due to insufficient primary rotational stability. It has been suggested that modular femoral components have a risk of fretting, corrosion, and mechanical failure, resulting in osteolysis and loosening $[10,11]$. In our case series, we identified only 1 case of osteolysis around the femoral stem with further aseptic loosening, with no evidence of gross metallic debris or blackening of the periprosthetic tissue observed during the stem revision surgery.

In this study, we used two types of modular stems. First-generation modular fluted tapered stems (Helios, Valencia, Biomet, Spain) were available in our hospital for use in 39 patients (47 hips) between 2001 and 2011. New generation cylindrical stems, anatomically bowed with a distal bullet-tip (Arcos, Zimmer, Biomet), were used in 17 patients (21 hips) after 2011. Broach proximal body was adapted to these stems. Cylindrical stems were superior to the fluted tapered stems to exhibit superior neutral alignment. These modular prostheses also had the versatility of high and standard offset. Therefore, hips achieving high offset did not have Trendelenburg gait after the operation.

\section{Future work}

Ceramic inner cups and heads can also be used with the new generation modular prosthesis type. As the number of surgeries using the new generation modular stems increases, future work to compare the results of fluted tapered and cylindrical stems will be necessary. With a long-term study, the results of THA with a ceramicceramic articulation can also be evaluated.

There are limitations in our study that warrant discussion. First, this is a retrospective study with no control group, which limits the strength of our analysis. Moreover, we did not compare the results of THA combined with shortening osteotomy between non-modular and modular stems. Second, all THAs were performed by 3 senior surgeons. Third, the follow-up period is still midterm, and the durability of these complex reconstructions must continue to be assessed in long-term follow-up studies. 


\section{Conclusion}

Cementless modular THA combined with sub-trochanteric transverse shortening osteotomy is a feasible option for treating high hip dislocations, with satisfactory and reliable 10-year clinical outcomes. Sufficient rotational stability of the cementless implant and union rates results in improved hip function, restoration of more normal limb lengths, and a low incidence of complications.

\section{Abbreviations}

THA: Total hip arthroplasty; HHS: Harris hip score.

\section{Acknowledgements}

None.

\section{Authors' contributions}

All authors read and approved the final manuscript.

\section{Funding}

None.

\section{Availability of data and materials}

The datasets used and/or analyzed during the current study are available from the corresponding author on reasonable request.

\section{Declarations}

\section{Ethics approval and consent to participate}

This study was conducted in accordance with the declaration of Helsinki with approval from the Istanbul Research and Training Hospital institutional Ethics Review Board (772-05/02/2016).

\section{Consent for publication}

Written informed consent to publish the clinical details and images of the patient was obtained.

\section{Competing interests}

The authors declare that they have no competing interests.

\section{Author details}

${ }^{1}$ Departments of Orthopaedics and Traumotology, Sakarya University Training and Research Hospital, 54050 Sakarya, Turkey. ${ }^{2}$ Departments of Orthopaedics and Traumotology, Istanbul Training and Research Hospital, Istanbul, Turkey. ${ }^{3}$ Departments of Orthopaedics and Traumotology, Ortopedkliniken Mälarsjukhuset, Eskilstuna, Sweden. ${ }^{4}$ Departments of Orthopaedics and Traumotology, Medipol University Hospital, Istanbul, Turkey.

Received: 7 December 2021 Accepted: 18 February 2022

Published online: 04 March 2022

\section{References}

1. Greber EM, Pelt CE, Gililland JM, Anderson MB, Erickson JA, Peters CL. Challenges in total hip arthroplasty in the setting of developmental dysplasia of the hip. J Arthroplasty. 2017;32(9S):S38-44. https://doi.org/ 10.1016/j.arth.2017.02.024.

2. Ollivier M, Abdel MP, Krych AJ, Trousdale RT, Berry DJ. Long-term results of total hip arthroplasty with shortening subtrochanteric osteotomy in Crowe IV developmental dysplasia. J Arthroplasty. 2016;31(8):1756-60. https://doi.org/10.1016/j.arth.2016.01.049.

3. Togrul E, Ozkan C, Kalaci A, Gülşen M. A new technique of subtrochanteric shortening in total hip replacement for Crowe type 3 to 4 dysplasia of the hip. J Arthroplasty. 2010;25(3):465-70. https://doi.org/10.1016/j. arth 2009.02 .023
4. Hartofilakidis G, Lampropoulou-Adamidou K, Karachalios TS. An attempt to throw light on congenital hip disease terminology and anticipation of clinical outcomes when treated with total hip arthroplasty. Hip Int. 2017;27(3):211-4. https://doi.org/10.5301/hipint.5000528.

5. Sakellariou VI, Christodoulou M, Sasalos G, Babis GC. Reconstruction of the acetabulum in developmental dysplasia of the hip in total hip replacement. Arch Bone Joint Surg. 2014;2(3):130-6.

6. Wu X, Li SH, Lou LM, Cai ZD. The techniques of soft tissue release and true socket reconstruction in total hip arthroplasty for patients with severe developmental dysplasia of the hip. Int Orthop. 2012;36(9):1795-801. https://doi.org/10.1007/s00264-012-1622-6.

7. Karachalios T, Hartofilakidis G. Congenital hip disease in adults: terminology, classification, pre-operative planning and management. J Bone Joint Surg Br. 2010;92(7):914-21. https://doi.org/10.1302/0301-620X.92B7. 24114.

8. Argenson JN, Ryembault E, Flecher X, Brassart N, Parratte S, Aubaniac JM. Three-dimensional anatomy of the hip in osteoarthritis after developmental dysplasia. J Bone Joint Surg Br. 2005;87(9):1192-6.

9. Noble PC, Kamaric E, Sugano N, et al. Three-dimensional shape of the dysplastic femur: implications for THR. Clin Orthop Relat Res. 2003:417:27-40.

10. Takao M, Ohzono K, Nishii T, Miki H, Nakamura N, Sugano N. Cementless modular total hip arthroplasty with subtrochanteric shortening osteotomy for hips with developmental dysplasia. J Bone Joint Surg Am. 2011;93(6):548-55. https://doi.org/10.2106/JBJS.I.01619.

11. Wang D, Li LL, Wang HY, Pei FX, Zhou ZK. Long-term results of cementless total hip arthroplasty with subtrochanteric shortening osteotomy in Crowe type IV developmental dysplasia. J Arthroplasty. 2017;32(4):12119. https://doi.org/10.1016/j.arth.2016.11.005.

12. Kilicoglu OI, Turker M, Akgul T, Yazicioglu O. Cementless total hip arthroplasty with modified oblique femoral shortening osteotomy in Crowe type IV congenital hip dislocation. J Arthroplasty. 2013;28(1):117-25. https://doi.org/10.1016/j.arth.2012.06.014.

13. Krych AJ, Howard JL, Trousdale RT, Cabanela ME, Berry DJ. Total hip arthroplasty with shortening subtrochanteric osteotomy in Crowe typeIV developmental dysplasia: surgical technique. J Bone Joint Surg Am. 2010;92(Suppl 1 Pt 2):176-87. https://doi.org/10.2106/JBJS.J.00061.

14. Rasmussen SW, Bak K, Toholm C. External compression of forearm nonunion. A report on 6 cases. Acta Orthop Scand. 1993;64(6):669-70.

15. Yasgur DJ, Stuchin SA, Adler EM, Di Cesare PE. Subtrochanteric femoral shortening osteotomy in total hip arthroplasty for high-riding developmental dislocation of the hip. J Arthroplasty. 1997;12(8):880-8.

16. Sener N, Tozun IR, Asik M. Femoral shortening and cementless arthroplasty in high congenital dislocation of the hip. J Arthroplasty. 2002;17(1):41-8.

17. Masonis JL, Patel JV, Miu A, et al. Subtrochanteric shortening and derotational osteotomy in primary total hip arthroplasty for patients with severe hip dysplasia: 5-year follow-up. J Arthroplasty. 2003;18(3 Suppl 1):68-73.

18. Park MS, Kim KH, Jeong WC. Transverse subtrochanteric shortening osteotomy in primary total hip arthroplasty for patients with severe hip developmental dysplasia. J Arthroplasty. 2007;22(7):1031-6.

19. Crowe JF, Mani VJ, Ranawat CS. Total hip replacement in congenital dislocation and dysplasia of the hip. J Bone Joint Surg Am. 1979:61:15-23.

20. Hartofilakidis G, Stamos K, loannidis TT. Low friction arthroplasty for old untreated congenital dislocation of the hip. J Bone Joint Surg Br. 1988;70:182-6.

21. Harris WH. Traumatic arthritis of the hip after dislocation and acetabular fractures: treatment by mold arthroplasty. An end-result study using a new method of result evaluation. J Bone Joint Surg Am. 1969:51(4):737-55.

22. Engh CA, Massin P, Suthers KE. Roentgenographic assessment of the biologic fixation of porous-surfaced femoral components. Clin Orthop Relat Res. 1990;257:107-28.

23. Ogawa H, Ito Y, Shinozaki M, Matsumoto K, Shimizu K. Subtrochanteric transverse shortening osteotomy in cementless total hip arthroplasty achieved using a modular stem. Orthopedics. 2011;34(3):170. https://doi. org/10.3928/01477447-20110124-24.

24. Rasi AM, Kazemian G, Khak M, Zarei R. Shortening subtrochanteric osteotomy and cup placement at true acetabulum in total hip arthroplasty of Crowe III-IV developmental dysplasia: results of midterm 
follow-up. Eur J Orthop Surg Traumatol. 2017. https://doi.org/10.1007/ s00590-017-2076-8.

25. Kelley SS. High hip center in revision arthroplasty. J Arthroplasty. 1994;9(5):503-10.

26. Thorup B, Mechlenburg I, Soballe K. Total hip replacement in the congenitally dislocated hip using the Paavilainen technique: 19 hips followed for 1.5-10 years. Acta Orthop. 2009;80(3):259-62. https://doi.org/10.3109/ 17453670902876789.

27. Hasegawa Y, Iwase T, Kanoh T, Seki T, Matsuoka A. Total hip arthroplasty for Crowe type IV developmental dysplasia. J Arthroplasty. 2012;27(9):1629-35. https://doi.org/10.1016/j.arth.2012.02.026.

28. Mu W, Yang D, Xu B, Mamtimin A, Guo W, Cao L. Midterm outcome of cementless total hip arthroplasty in Crowe IV-Hartofilakidis Type III developmental dysplasia of the hip. J Arthroplasty. 2016;31(3):668-75. https:// doi.org/10.1016/j.arth.2015.10.011.

29. Zhu J, Shen C, Chen X, Cui Y, Peng J, Cai G. Total hip arthroplasty with a non-modular conical stem and transverse subtrochanteric osteotomy in treatment of high dislocated hips. J Arthroplasty. 2015;30(4):611-4. https://doi.org/10.1016/j.arth.2014.11.002.

30. Abdel MP, Parratte $S$, Blanc $G$, et al. No benefit of patient-specific instrumentation in TKA on functional and gait outcomes: a randomized clinical trial. Clin Orthop Relat Res. 2014;472(8):2468-76. https://doi.org/10.1007/ s11999-014-3544-7.

31. Sofu H, Kockara N, Gursu S, Issin A, Oner A, Sahin V. Transverse subtrochanteric shortening osteotomy during cementless total hip arthroplasty in Crowe Type-III or IV developmental dysplasia. J Arthroplasty. 2015;30(6):1019-23. https://doi.org/10.1016/j.arth.2015.01.045.

32. Akiyama H, Kawanabe K, Yamamoto K, et al. Cemented total hip arthroplasty with subtrochanteric femoral shortening transverse osteotomy for severely dislocated hips: outcome with a 3- to 10-year follow-up period. J Orthop Sci. 2011;16(3):270-7.

33. Yalcin N, Kilicarslan K, Karatas F, Mutlu T, Yildirim H. Cementless total hip arthroplasty with subtrochanteric transverse shortening osteotomy for severely dysplastic or dislocated hips. Hip Int. 2010;20(1):87-93.

34. Muratli KS, Karatosun V, Uzun B, Celik S. Subtrochanteric shortening in total hip arthroplasty: biomechanical comparison of four techniques. J Arthroplasty. 2014;29(4):836-42. https://doi.org/10.1016/j.arth.2013.09. 004.

35. Li C, Zhang C, Zhang M, Ding Y. Comparison of transverse and modified subtrochanteric femoral shortening osteotomy in total hip arthroplasty for developmental dysplasia of hip: a meta-analysis. BMC Musculoskelet Disord. 2014;15:331. https://doi.org/10.1186/1471-2474-15-331.

36. Onodera S, Majima T, Ito H, Matsuno T, Kishimoto T, Minami A. Cementless total hip arthroplasty using the modular S-ROM prosthesis combined with corrective proximal femoral osteotomy. J Arthroplasty. 2006;21:664-9.

37. Biant LC, Bruce WJ, Assini JB, Walker PM, Walsh WR. Primary total hip arthroplasty in severe developmental dysplasia of the hip. Ten-year results using a cementless modular stem. J Arthroplasty. 2009;24:27-32.

\section{Publisher's Note}

Springer Nature remains neutral with regard to jurisdictional claims in published maps and institutional affiliations.

Ready to submit your research? Choose BMC and benefit from:

- fast, convenient online submission

- thorough peer review by experienced researchers in your field

- rapid publication on acceptance

- support for research data, including large and complex data types

- gold Open Access which fosters wider collaboration and increased citations

- maximum visibility for your research: over 100M website views per year

At BMC, research is always in progress.

Learn more biomedcentral.com/submissions 